\title{
An Intersectional Analysis of the English-Competency Experiences of International Teaching Assistants
}

\author{
Ashish Agrawal \\ National Institute of Technical Teachers Training and \\ Research, Chennai, India \\ Lisa D. McNair \\ Virginia Tech, USA
}

\begin{abstract}
International graduate students serving as teaching assistants constitute a major component of the teaching of undergraduate students at U.S. universities, particularly in engineering. Prior literature on these international teaching assistants (ITAs) generally characterizes their linguistic experiences as challenges. This characterization can be attributed to an institutional environment that is reluctant to accommodate diverse ways of speaking English. This study applies an intersectionality framework to explore the variations in ITAs' Englishlanguage experiences and the influence of the academic context on these experiences using semi-structured interviews and weekly reflections collected from seven engineering ITAs over a semester. Results of data analysis suggest that ITAs' English proficiency varies based on their prior exposure to English in their home countries, and their English competence improves through their teaching experiences in the United States. Participants' experiences also highlight a perceived expectation to not only use English while teaching but also to adapt to American English.
\end{abstract}

Keywords: English competency, international teaching assistants, intersectionality, teaching experiences at U.S. universities 


\section{INTRODUCTION}

International students form a significant portion of the graduate student population pursuing master's and doctoral degrees at U.S. universities, especially in engineering. In Fall 2018, 51.2\% of the 158,583 graduate students enrolled in engineering at U.S. universities were international students (Okahana \& Zhou, 2019). Data from the Institute of International Education (2019) suggest that about one-third of these international graduate students receive their funding from U.S. universities in the form of teaching or research assistantships. As part of their teaching assistant (TA) responsibilities, these graduate students, referred to here as international teaching assistants (ITAs), generally serve as laboratory assistants, lead recitation sessions, grade tests and assignments, prepare instructional materials, proctor tests, and handle students' questions and queries for various undergraduate courses. At some universities, ITAs also teach introductory courses in their disciplines as course instructors.

In this context, most of the literature on ITAs characterizes their linguistic experiences as challenges (e.g., see Adebayo \& Allen, 2020; Arshavskaya, 2015; Fitch \& Morgan, 2003). This literature reports ITAs' linguistic proficiency as lacking even if they have had significant exposure to English as a medium of instruction and communication through their prior educational or work experiences. Such deficit characterization of ITAs' English proficiency can be attributed to an institutional environment that is reluctant to accommodate differences in ways of speaking English (Jenkins, 2014).

This study uses the critical framework of intersectionality to explore (a) variations in ITAs' English-language experiences in the U.S. undergraduate engineering context and (b) the role of academic context in shaping these experiences. Intersectionality allowed us to understand how ITAs' backgrounds and academic context intersect with the identity construct of ITAs' "foreignness" and how this intersection leads to linguistic advantages and disadvantages.

\section{LITERATURE REVIEW}

Much of the research on ITAs' self-perception of their linguistic competence has highlighted communication challenges they face. In terms of semantics, Zhou (2014) noted how ITAs at times find it difficult to respond students' questions and comments due to limited vocabulary, which also can cause difficulty in speaking grammatically correct sentences and hence effectively expressing their thoughts (Chiang, 2011, 2016). In terms of pronunciation, Adebayo and Allen (2020) highlighted that several ITAs perceived their communication fluency and accented English as challenges that create difficulties in being understood by students. ITAs also face challenges in understanding spoken English. For example, in studies by Arshavskaya (2015) and Adebayo and Allen (2020), several ITAs expressed challenges in fully understanding the undergraduate students they taught. While these issues affect ITAs with limited prior exposure to English, those ITAs who have been significantly exposed to English as a medium of instruction and communication in their home countries or the United 
States also experience communication challenges. They feel worried that their English communication is not as good as that of native speakers and hence lose confidence as a teacher and a communicator (Kasztalska, 2018).

Research on ITAs' linguistic competence in the United States has also highlighted the challenges faced by students taught by ITAs. For example, in the study conducted by Fitch and Morgan (2003), students complained about not being able to understand their ITAs, and hence saw themselves as victims. This sense of miscommunication was also extended to ITAs who possessed a significant amount of English proficiency through their extensive use of the language for academic and communication purposes before coming to the United States. In the latter case, the students complained that the ITA did not speak "the right kind of English" (p. 303) and that the ITA's foreign accent posed problems in understanding them. Similarly, in the studies conducted by Chiang (2011, 2016), several students noted their inability to understand their ITAs due to the ITAs' inability to correctly pronounce some words or effectively express themselves. Some students also noted that their ITAs were unable to understand the questions asked of them. As a result, U.S. students often resist ITAs and prefer domestic TAs and instructors (Arshavskaya, 2015).

While both ITAs and the students they teach face genuine communication challenges due to problems related to the ITAs' English proficiency, these problems need to be seen in the context of the educational environments that view ITAs as nonnative English speakers and their different ways of speaking English as a problem (Jenkins, 2014). This deficit-based outlook exemplifies the fallacy of determining a native speaker as White and preferably from an English-speaking country such as the United States, the United Kingdom, or Canada. Thus, ITAs from countries such as India, Nigeria, or Kenya, who have developed significant levels of English-communication proficiency due to their exposure to the language in academic and work settings, are more overtly treated as nonnative speakers due to their different vocabulary and accents, and perhaps their skin color (Sterzuk, 2015). Munro (2003) argued that the objection to foreign accents has often more to do with an unwillingness to accept differences and less with difficulties in comprehension. Linking language to race-based discrimination, Pimentel (2011) noted that "language [often] serves as a proxy for race" (p. 341). Along similar lines, Lee and Rice (2007), in their study of international students' experiences at a U.S. university, found that students from India, Latin America, Asia, and the Middle East reported considerable discrimination related to culture or language compared with those from Europe, Canada, and New Zealand. The authors attributed this phenomenon to neo-racism, which rationalizes discrimination against people of color by attributing it to "cultural difference or national origin rather than by physical characteristics alone" (p. 389).

Research conducted from this perspective superficially explores the challenges faced by ITAs in a new linguistic and educational setting with an attempt to "fix" their English (Jenkins, 2014). Guided by findings from such studies, several universities offer training programs to ITAs that try to Americanize their accents and ways of speaking (Zhou, 2009) without exploring 
"how the locals might adapt their own language practices" (Jenkins, 2014, p. 20) to communicate with ITAs.

An educational environment that regards ITAs' linguistic competence as deficient aggravates the linguistic challenges faced by ITAs. Such an environment may lead ITAs to view their own English as lacking, further developing their anxiety about interacting with students (Bauer, 1996; Zhou, 2014) and insecurities about their teaching competence (Kasztalska, 2018; Wang, 2016). It also heightens negative biases in students toward ITAs. Due to these negative biases, students often complain about an ITA's English (Hebbani \& Hendrix, 2014), and some even attempt to "discredit [an ITA] as a teacher in front of the whole class" (Kasztalska, 2018, p. 166).

Such an academic environment that problematizes ITAs' linguistic competencies not only negatively influences ITAs' performance and experiences but also adversely affects the internationalization goals of universities. Ryan (2011) argued that instead of problematizing international students and scholars and expecting them to adapt to the existing educational paradigm, the universities should view them as a source of internationalization through exchange of ideas and beliefs to inform cross-cultural teaching.

In terms of language, ITAs bring two major benefits to a U.S. classroom. First, a majority of ITAs are multilingual speakers - that is, they can speak one or more languages in addition to English. Canagarajah (2011) noted that multilingual speakers are able to "shuttle between languages, treating the diverse languages that form their repertoire as an integrated system" (p. 401). This ability to shuttle between languages is referred to as translingualism, which can be used as a pedagogical tool to effectively communicate with and teach individuals from diverse backgrounds (Zheng, 2017). Second, ITAs bring with them diverse ways of speaking English, which can be used to expose students to the World Englishes perspective. A World Englishes perspective celebrates the different varieties of English without preferring one over another (Zhou, 2009), and can be used to increase students' global competence. However, the value of such exchanges across borders is rarely recognized (Ryan, 2011), particularly as a contribution by ITAs. On the contrary, in U.S. academic contexts there exist implicit expectations that ITAs adapt to a "standard" English that is assumed to be stable despite existing in settings that are increasingly global and diverse (Sterzuk, 2015). As Zheng (2017) and Zhou (2009) argued, an academic context that wishes to realize the benefits ITAs bring should recognize this potential and encourage ITAs to use their multilingual skills and diverse ways of speaking English.

\section{Research Questions}

Based on the above discussion, we argue that there are nuances present in ITAs' linguistic experiences beyond simply characterizing them as "challenges." In fact, as Heng (2019) suggested, international student experiences diverge along several lines including their year of study and academic discipline. Moreover, as discussed above, the academic context in which ITAs are situated also plays an 
important role in shaping their linguistic experiences. Our research explores the following questions:

RQ1: What variations are present in the English-language experiences of ITAs in U.S. undergraduate engineering classes?

RQ2: How does the academic context shape ITAs' linguistic experiences?

Here we define an ITA as an international student pursuing a master's or doctoral degree, employed as a teaching assistant, and holding a nonimmigrant student visa in the United States. Additionally, the ITA must have completed their K-12 and undergraduate education outside the United States. Guided by the works of scholars discussed above (e.g., Jenkins, 2014; Kasztalska, 2018; Zhou, 2009), we focus on the component of the academic context that is an institutional environment impacted by student and faculty attitudes toward and expectations for ITAs' language usage, which in turn is also reflected in ITAs' self-perception of their linguistic abilities. Given the importance of the academic discipline in shaping student experiences (Heng, 2019), we also include the nature of engineering knowledge and teaching within the ambit of academic context. Engineering, for example, draws heavily from knowledge in math and science (Cunningham \& Kelly, 2017) and involves extensive use of graphs, equations, and other forms of representation. Moreover, engineering is dominated by course activities that stress fact-finding and reporting, and well-structured problemsolving (Jonassen, 2014) compared to more intensively language-based disciplines such as English, history, or sociology that value face-to-face meetings involving discussions and debates on the course topics (Lindblom-Ylänne et al., 2006) as well as assignments that require extensive writing.

\section{Theoretical Framework: Intersectionality}

To address these research questions, we have used intersectionality as the theoretical framework to guide this study. While scholarship has extended intersectional work to a wide range of identity markers, the term "intersectionality" was coined by legal scholar Kimberle Crenshaw (1989), who argued that existing feminist politics discriminated against Black women because of their race while antiracist politics ignored Black women due to their gender. Hence, she advocated the importance of addressing the prejudices faced by Black women from an intersectional approach - that is, by looking at the ways in which race and gender interact to shape their experiences. Contemporary scholars such as Hancock (2007), Bedolla (2007), and Collins and Bilge (2016) have further advanced intersectional work through inclusion of a wider array of social identities such as class, ethnicity, and sexuality to understand the lived experiences of people.

Intersectionality is a complex theory to apply because of its dynamic and evolving nature. Scholars are constantly refining its parameters and ways to use it (Bruning et al., 2015). For example, Hancock (2007) noted that an intersectional analysis rejects the additive model, which assumes that if one keeps on adding 
social categories, the experiences of privilege or oppression of individuals can be understood. Instead, researchers should identify ways that allow categories to intertwine or intersect. She further added that there is a tremendous variation in experiences of individuals within each category and hence there is no one way to understand foreignness or Whiteness or masculinity or poverty, etc. She also warned against using the preexisting categories such as race or gender as dividing lines. Rather, she advocated for conceptualizing categories of difference based on "dynamic interaction between institutional and individual factors" (p.73). Bedolla (2007) expanded on this approach by highlighting the need to study experiences on micro- and macro-levels. She suggests that at the micro-level, one's experiences are constituted due to a complex interaction of several individual factors. Hence, one's experiences can simultaneously encompass advantages due to one factor and disadvantages due to another. At the macro-level, intersectionality situates individual experiences within the larger institutional, social, and historical contexts.

Contemporary scholars have used intersectionality as a research tool to study experiences at the individual level while illuminating contextual factors that create power differentials resulting in advantages and disadvantages. For example, using an intersectional lens, Bruning et al. (2015) found that one's family's socioeconomic standing, racial positioning within the society, and ethnic identity created context that sustained or deterred female students' decisions to continue with engineering in college. Similarly, Little (2016) used intersectionality to explore the influence of individual and institutional factors to understand how ITAs receive and respond to student feedback, finding that a complex interaction of individual attributes such as patience in helping students, a cheerful personality, and correct estimation of students' abilities, as well as institutional factors such as class size, student-to-teacher ratio, and departmental policies, determined how each ITA dealt with student feedback. Jones et al. (2020) used an intersectional lens to explore the influence of the dominant norms in terms of perceived professor authority and communication expectations in the context of a predominantly White U.S. university on ITAs' self-perceptions of their authority and resulting identity construction as a teacher and a learner.

Our work extends the application of intersectionality to understand the role of academic context in shaping ITAs' English-language experiences. As discussed above, intersectionality recognizes variations in the experiences of a social group while highlighting the role of contextual factors in shaping individuals' experiences. Hence, this framework can help illuminate critical, underexamined components of ITAs' English-language experiences in U.S. engineering education contexts.

\section{METHOD}

To address the research questions guiding this study, qualitative data were collected as part of a larger study that aimed at exploring the overall teaching experiences of ITAs in U.S. engineering classrooms (Agrawal et al., 2018). Two findings motivated the topic for this article from the larger study. First, six out of 
seven participants noted their English competency as a major factor that shaped their teaching experiences. Second, participants described their Englishcompetency experiences in ways that illustrated complexities that are understudied in the scholarship on ITAs' linguistic experiences.

\section{Research Site and Participants}

The participants for the study included seven ITAs teaching engineering courses at a large mid-Atlantic land-grant research university located in a rural setting in the United States. The university's international graduate student enrollment in engineering in the last few years has ranged between $55 \%$ and $60 \%$, which is very similar to the national average of 51.2\% (Okahana \& Zhou, 2019).

The focus of this study on engineering ITAs was also deliberate. As discussed above, engineering programs enroll a large percentage of international graduate students, and they also employ a large number of ITAs. Since the nature of teaching and learning in engineering is different from disciplines that are more intensively language based, the linguistic experiences of engineering ITAs need to be separately studied.

By collecting data through reflection and conversations with ITAs, our study gave them an opportunity to share their experiences. Hebbani and Hendrix (2014) argued that prior research on ITAs has generally been "ignoring the voices of the ITAs themselves" (p. 62) by either studying student experiences with ITAs or examining ITA training programs. Our study was approved by the Institutional Review Board at Virginia Tech and the Ethics in Research Committee at the University of Cape Town.

Participants were recruited using methods such as electronic advertisement, in-person recruitment, flyers, and snowball sampling. While the snowball sampling method might have led to recruitment of friends and acquaintances of initial respondents leading to a selection bias in the participant pool, it served as an important recruitment tool given the time commitment required for the study.

We started the study with 10 ITAs but three of them dropped out in the first 3 weeks citing competing priorities. The remaining seven (ITA1 through ITA7) completed the study, and the term "participant" refers to these seven ITAs henceforth. The participants for the study represented variations in terms of selfidentified gender including five male and two female participants, and they taught courses at different levels including sophomore, junior, and senior classes. Table 1 provides other demographic details of the participants including their home country, year in the $\mathrm{PhD}$ program, teaching responsibilities, prior teaching experience, and prior exposure to English in home country. While the study was open for master's students too, coincidently all participants were pursuing doctoral degrees. Note that Table 1 excludes participant pseudonyms to preserve anonymity. 
Table 1: Participant Demographic Details

\begin{tabular}{|c|c|c|c|c|c|}
\hline $\begin{array}{l}\text { Home } \\
\text { country }\end{array}$ & $\begin{array}{l}\text { Year } \\
\text { in PhD }\end{array}$ & $\begin{array}{l}\text { Major teaching } \\
\text { responsibilities }\end{array}$ & $\begin{array}{l}\text { Prior TA } \\
\text { experience } \\
\text { in the } \\
\text { United } \\
\text { States }\end{array}$ & $\begin{array}{l}\text { Prior TA } \\
\text { experience } \\
\text { with the } \\
\text { same } \\
\text { course }\end{array}$ & $\begin{array}{l}\text { Prior exposure to } \\
\text { English in home } \\
\text { country }\end{array}$ \\
\hline China & $1 \mathrm{st}$ & $\begin{array}{l}\text { Instructing lab, } \\
\text { grading }\end{array}$ & No & No & $\begin{array}{l}\text { Studied English } \\
\text { as a language } \\
\text { course in school }\end{array}$ \\
\hline China $^{a}$ & 4th & $\begin{array}{l}\text { Grading, } \\
\text { holding office } \\
\text { hours }\end{array}$ & Yes & Yes & $\begin{array}{l}\text { Studied English } \\
\text { as a language } \\
\text { course in school }\end{array}$ \\
\hline Egypt & 5th & $\begin{array}{l}\text { Holding office } \\
\text { hours }\end{array}$ & Yes & No & $\begin{array}{l}\text { Used English as } \\
\text { a medium of } \\
\text { instruction }\end{array}$ \\
\hline India & $3 \mathrm{rd}$ & $\begin{array}{l}\text { Grading, } \\
\text { holding office } \\
\text { hours }\end{array}$ & Yes & No & $\begin{array}{l}\text { Studied English } \\
\text { as a language } \\
\text { course in school; } \\
\text { used English in } \\
\text { work } \\
\text { environment }\end{array}$ \\
\hline India & $3 \mathrm{rd}$ & $\begin{array}{l}\text { Grading, } \\
\text { holding office } \\
\text { hours }\end{array}$ & Yes & No & $\begin{array}{l}\text { Used English as } \\
\text { a medium of } \\
\text { instruction }\end{array}$ \\
\hline India $^{b}$ & $3 \mathrm{rd}$ & $\begin{array}{l}\text { Making } \\
\text { assignments, } \\
\text { grading; } \\
\text { holding office } \\
\text { hours, } \\
\text { instructing lab }\end{array}$ & Yes & Yes/No & $\begin{array}{l}\text { Studied English } \\
\text { as a language } \\
\text { course in school }\end{array}$ \\
\hline Iran & $2 \mathrm{nd}$ & $\begin{array}{l}\text { Grading, } \\
\text { holding office } \\
\text { hours }\end{array}$ & Yes & Yes & $\begin{array}{l}\text { Studied English } \\
\text { as a language } \\
\text { course in school; } \\
\text { interacted with } \\
\text { others in English } \\
\text { during } \\
\text { undergraduate } \\
\text { studies }\end{array}$ \\
\hline
\end{tabular}

Note $: \mathrm{TA}=$ teaching assistantship. ${ }^{\mathrm{a}}$ Participant was teaching both a graduate course and an undergraduate course; the study focused on their experiences in the undergraduate course.

${ }^{\mathrm{b}}$ Participant was teaching two undergraduate courses; the details about their teaching responsibilities in the two courses are separated by a semi-colon. 


\section{Data Collection}

We collected data in the form of semi-structured interviews and weekly reflections over a period of one semester. We conducted interviews at three critical junctures during the semester. These interviews lasted approximately $25-$ 60 min each. The first interview was during the second week of the semester and aimed at collecting participants' demographic data and background information. During this interview, we also asked the ITAs questions about their preparedness for teaching the course and the support provided by the university, the engineering department, and the course instructor.

The second interview was two-thirds of the way through the semester (Weeks 10-12) and aimed at giving the ITAs an opportunity to reflect on their ongoing experiences while these experiences were still fresh in their memory. During this interview, we asked about their teaching experiences, navigational strategies, and factors leading to these experiences.

The third and final interview was at the beginning of the next semester and aimed to holistically capture participants' teaching experiences during the semester with more focus on their significant experiences during the second half of the past semester. Additionally, we asked about differences in teaching between the United States and their home countries, ways to improve the future course offerings, and suggestions for future TAs.

We collected weekly reflections from the participants each week starting the second week until the end of the semester via email prompts. Participants sent their reflections in the form of email responses to these prompts. We asked clarification questions, if necessary. Each set of prompts asked participants to reflect on the most significant experience, challenge, or reward that they experienced during the week. Besides capturing participants' experiences on a regular basis, these reflections helped develop probes for the second and the third interviews.

\section{Data Analysis}

Data were analyzed using DedooseTM (Dedoose, Hermosa Beach, CA) software in a three-stage process guided by the recommendations from intersectionality scholars including Hancock (2007), Bedolla (2007), and Collins and Bilge (2016). The first stage involved thematic coding to identify themes in participants' linguistic experiences. These themes related to challenges and confidence in teaching in English, different ways of speaking English, changes in participants' linguistic experiences over time, and use of native language in instruction.

The second stage of analysis involved identifying individual or contextual factors that shaped participants' linguistic experiences (Bedolla, 2007). Here individual factors included participants' backgrounds and prior experiences, and contextual factors related to ITAs' self-perception of student and faculty attitudes 
and expectations in relation to language use in engineering education settings. Thus, while the individual factors illuminated variations in participants' experiences (Collins \& Bilge, 2016; Hancock, 2007), the contextual factors highlighted the different ways in which the academic context shaped ITAs' linguistic experiences (Bedolla, 2007).

The third and the final stage of analysis involved identifying "categories of difference" (Hancock, 2007) within both individual and contextual factors. Following Hancock's (2007) suggestions, we did not start with ITAs' social identities as the dividing lines for creating categories. Instead, these categories were grounded in data. The first author completed the coding. We then modified the codes based on several discussions, along with a second professor and a graduate student in the research group.

\section{RESULTS}

The results of our analysis are presented in two sections. The first section discusses variations across participants in their English-language experiences and the different individual factors related to ITAs' backgrounds and prior experiences that shaped these English-language experiences. The second section elaborates on how the academic context intersected with ITAs' foreignness, thus shaping their linguistic experiences. Example quotes are used to represent participants' experiences. Note that the example quotes were taken verbatim from interview transcripts and weekly reflections, and hence reflect the spoken language of the participants rather than standard academic English. In addition, to preserve anonymity, the gender-neutral plural pronouns are used for all participants.

\section{Variations in ITAs' Experiences}

As discussed above, ITAs' English competency has generally been viewed as deficient in the U.S. academy. However, the ITAs in this study noted both confidence and challenges related to their English communication. These experiences were shaped by a complex intersection of three individual factors with each other: ITAs' prior exposure to English before coming to the United States, diverse ways of speaking English, and teaching experience in the United States.

\section{Prior Exposure to English}

Participants' exposure to English as a medium of instruction or communication in their home country was a significant factor in shaping their English-language experiences. As noted in Table 1, participants had varied levels of prior exposure to English. ITAs who noted confidence in their communication skills had already developed some competence in English as a medium of 
communication during their education or work experience before coming to the United States. For example, one participant reflected during the final interview:

If I know what I'm going to talk [about], I can frame the sentences decent enough and I can make the idea go through. If I have to explain a concept that I'm good at and I know what I'm talking about, it has never been an issue of telling these things. (ITA5)

As the above quote suggests, this participant felt confident in their ability to communicate the course content to students and highlighted that they had never faced communication issues while teaching. This participant had already developed some level of fluency in English during their prior educational and work experiences, and also had experience working and communicating with people from "different backgrounds and cultures of [home country] and languages" (Interview 1). Similarly, another participant reflected in a weekly reflection:

[Last week] a girl came during my Friday office hours and sat there solving the assignment... She had a tough time initially because she had forgotten most of her linear algebra. But then we both went about the question step-by-step and then she grew in confidence and went on to solve most of the parts on her own. [...] My communication skills and also the quality to perceive what the person sitting opposite to you is thinking helps in this experience. (ITA3)

Like ITA5, this participant had developed English proficiency before coming to the United States. In their home country, the participant had studied at schools where the medium of instruction was English, which helped them develop communication skills in English. This participant noted in an interview that they had not faced any significant communication challenges in teaching and highlighted that "the whole credit [for this achievement] goes to [their] school [in their home country]" (Interview 1).

Participants who emphasized communication challenges had little exposure to English as a medium of communication before coming to the United States. For them, studying and teaching in the United States was the first time they were exposed to English as a medium of communication and instruction. For example, one participant reflecting on an early experience of teaching a lecture class noted the realization that they were "not [always] clear in getting the ideas across to the students" (ITA2, Interview 2). For other participants, these communication challenges were more specific and pertained to both listening and speaking. For example, one participant felt that they could not understand their students as they "speak very quickly to ask some questions" (ITA6, Interview 3). Another ITA reflected how they, at times, could not follow students while conversing with 
them. At other times, they found it difficult to express their thoughts to students. As the participant explained:

The first thing is about the listening part—when they ask some questions, maybe they speak too fast and I cannot follow them... The second difficulty is that sometimes it's hard to explain some [concepts] using English because it is not my first language and sometimes you may [be] stuck in some important sentence. (ITA7, Interview 3)

As highlighted in the above quote, the ITA experienced difficulties in understanding the spoken words of their students and communicating their thoughts due to challenges with framing sentences. These issues in listening and speaking could be due to the ITAs' lack of semantic (i.e., pertaining to the meaning of words and appropriate word usage) or syntactic (i.e., related to using grammatically correctness) knowledge of American English, which can be attributed to their lack of experience with English communication.

It is important to highlight that ITAs who noted facing communication challenges were exposed to English only as a language course in school in their home countries. While explicitly noted by only one participant, they also learned English to take tests such as the IELTS, TOEFL, and GRE required to apply to graduate school in the United States. Since their use of English in educational settings was limited to learning it as a course or to succeed in tests, it was insufficient to develop their English proficiency, especially in terms of understanding spoken English.

\section{Diverse Ways of Speaking English}

Regardless of their prior exposure to English, participants' communication proficiency was influenced by different ways of speaking English-that is, differences between their expressions, conventions, or pronunciation versus those used in American English. These differences often led to misunderstandings and confusions between the ITA and their students. For example, one ITA described how misunderstandings happened with students due to a difference in the way they respond to question tags. This participant noted that in their home country, people answer the question in the question tag in contrast to the United States where people respond to the statement preceding the question tag. The participant explained this difference by drawing a chart (Figure 1). As can be seen in the figure, the same question from a student has two different and opposite responses in the two countries, leading to misunderstanding. 


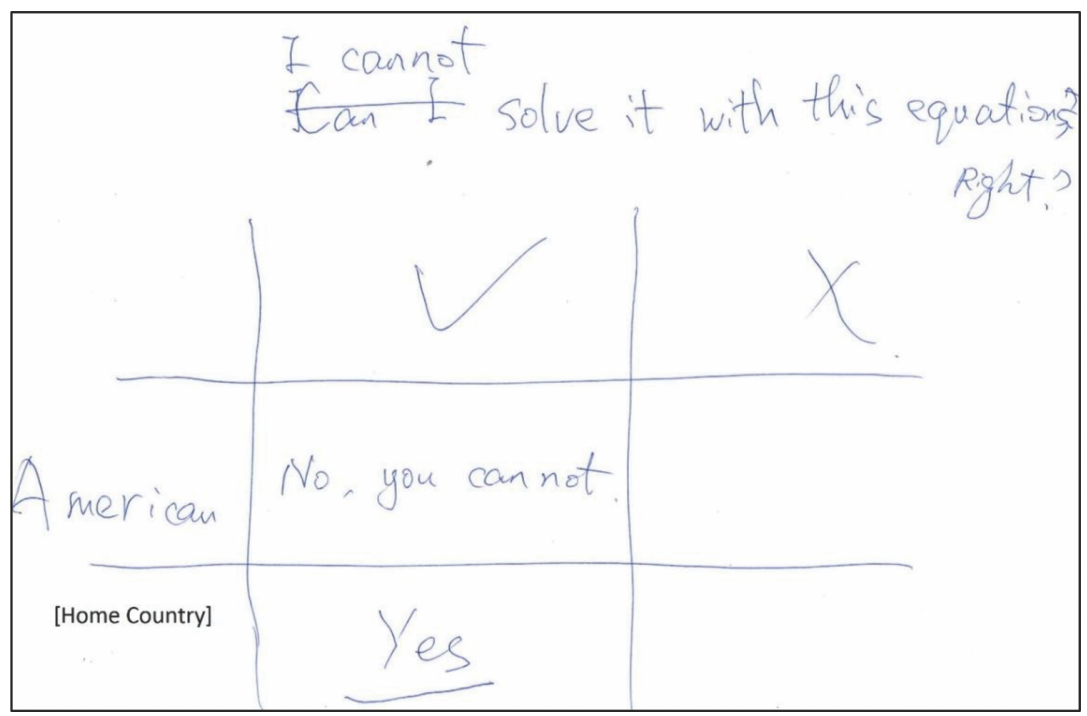

Figure 1: Differences in Responses to Question Tags

Another ITA described their confusion with the terminology that is typical of the U.S. educational setting and the different accents used in American English during their first semester of teaching. This participant noted:

Even in my first semester [of teaching], I would get confused by freshmen, junior, sophomore, senior - is it first, second, third year, fourth year? These are new terminology [for international students]. Then, there are a few things, there are some accents. In my first semester, I used to say array, A-R-R-A-Y [phonetic pronunciation: æreI], but in US, it's array [phonetic pronunciation: ə'reI]. (ITA3, Interview 3)

\section{Teaching Experience in the United States}

Participants' English competency, however, was not static. As they gained more exposure to teaching in English over time, they improved both their English competency and their general communication skills. For example, as noted in the above quote, ITA3 faced confusion due to different terminology and accents used in the United States only during their first semester of teaching. In the subsequent semesters, they got used to the terminology and accents and did not face such challenges. Similarly, ITA7 noted during the final interview that a semester of teaching improved their listening skills. The participant explained that at the beginning of the semester, they had to "ask them [students] to repeat [their questions] several times" as the participant could not understand their questions. However, by the end of the semester, the ITA was able to "adapt to their [students'] speech speed" (ITA7, Interview 3) leading to smoother communication. 
Another participant reflected in the final interview how their teaching experience helped them improve their general communication skills:

In terms of skills and all, I would say that trying to communicate few ideas that you yourself understand very well, but trying to communicate those to other people... I think that skill set, I think I definitely have improved on the last semester. (ITA2)

As reflected in the quote, the teaching experience helped the participant improve their ability to communicate ideas to a group of people in an educational setting. The participant further added that the teaching experience also helped them improve their ability to present course materials to students.

\section{Role of the Academic Context}

While the individual factors characterized by participants' backgrounds and experiences led to variations in their English-language experiences, intersections between academic context and these individual factors also shaped ITAs' linguistic experiences. The academic context influenced participants' linguistic experiences in three ways: preference for English over native language, adaptation to American English, and use of written representations.

\section{Preference for English Over Native Language}

All participants spoke at least one language other than English. Given a large percentage of international students at the undergraduate level (Okahana \& Zhou, 2019), participants sometimes taught students who were from their home country and spoke with the participants in their native language. These experiences provide important insights into the status of English language in educational settings as experienced by the participants.

Two participants recounted incidences related to the use of native language during teaching. While both could have used the native language to better explain course concepts to students, they had varying opinions toward using it. One of them was open to using their native language during teaching and noted that "sometimes, they [the students] may like to speak [in native language] if there is no other people [around]" (ITA6, Interview 3). Thus, the students could overcome the language barrier leading to a better understanding of the course. However, based on this quote, it seems that students felt a bit of discomfort in speaking their native language as they used it to communicate with the ITA only when other students were not present.

On the other hand, the other participant completely avoided speaking with students in their native language during office hours:

Last year I had two students - they just came to the office and started talk [with me in my native language]. I tried to answer them in English, because my friend told me that it is not something professional to just speak in different language [i.e., one's own native language] with other student. (ITA1, Interview 2) 
The social aspect of not being "professional" outweighed the potential of helping students to understand the course topics better. On further probing, the participant said that also their doctoral supervisor had strictly advised against using any language other than English in educational settings. This example, along with the previous one of noting the discomfort of students in using their native language, highlights how ITAs respond to the academic context by selecting English over other languages, even in situations where use of native language could improve understanding.

\section{Adaptation to American English}

Participants' experiences also point to the privileging of American English as it is spoken locally. As discussed above, participants improved their English competency as they gained more teaching experience in the United States. However, this improvement in their communication proficiency pointed to a clear preference for the English prevalent in the United States over other kinds of English. For example, ITA3, who had developed English proficiency before coming to the United States and initially struggled with terminology and accents specific to U.S. settings, as described above, noted acclimating to local terminology and accents instead of using these differences as teachable moments for students. Similarly, another ITA who initially experienced difficulties with English communication noted navigating this challenge in a way that implicitly assumes that the students who are native speakers of English are appropriately communicating, versus the ITA, who needs to move up to the level of students to be a better communicator. As the participant reflected:

Those American students, they talk really fast especially when they ask questions. At first, I have to ask them to repeat several times but finally, I think, I adapt to their speech speed and it makes the communication more smoothly. (ITA7, Interview 3)

As this quote suggests, the participant navigated the challenge they experienced with listening and comprehending by adapting their own "speech speed." It is possible that the ITA experienced this challenge due to issues with their own listening competency and limited experience with English communication. However, it should be particularly noted here that they did not ask the students to slow down even though they thought that the students spoke fast. Rather, they adjusted their own listening to understand what the students were saying.

\section{Use of Written Representations}

While the academic context generally presented challenges for ITAs due to a preference for American English, the disciplinary context of engineering mitigated some of these challenges. Although discussed by only one participant, the nature of engineering knowledge, which heavily draws from knowledge in science and math, helped them communicate with students using different forms of representations, such as graphs, diagrams, and equations, in written form. As the ITA noted: 
Sometimes it's hard to explain some [concepts] using English because it is not my first language and sometimes you may [get] stuck in some important sentence. At that time, I will use the whiteboards and to use of graphs because we all understand graphs. I will let the graphs to help me to make the explanations. (ITA7, Interview 3)

Thus, the participant overcame the challenges they faced due to their lack of proficiency in oral communication.

\section{DISCUSSION AND CONCLUSION}

In this paper, we explored the complexities of ITAs' linguistic experiences at both micro- and macro-levels drawing on insights from intersectionality theory (Bedolla, 2007). At the micro-level, we identified individual factors related to participants' backgrounds and prior experiences that intersected with each other, leading to variations in their linguistic experiences. These factors include exposure to English before coming to the United States and prior teaching experience in the United States. Participants with prior exposure to English during their educational and work experiences in their home countries generally expressed confidence in their communication proficiency with difficulties only due to a lack of familiarity with vocabulary and accents used in American English. On the other hand, ITAs with little prior exposure to English expressed communication challenges due to both difficulties in understanding spoken English and use of different ways of speaking English. However, regardless of ITAs' prior exposure to English, their linguistic challenges started gradually subsiding as they gained more teaching experience and exposure to American English after arriving in the United States. Thus, the linguistic challenges were more prominent for ITAs lying at the intersection of being novice and not being able to develop English proficiency in their home countries.

At the macro-level, however, even the ITAs with English proficiency encountered linguistic challenges due to ways in which the academic context intersected with ITAs" "foreignness," an identity category represented by their multilingual abilities and different ways of speaking English. In this study, ITAs reported being discouraged from fully taking advantage of their translingual abilities - that is, the ability to use different languages in their teaching. One participant was told by their advisor and their peers that using other languages in educational settings is not professional, and they therefore did not use common native language with students. While another participant did use their native language to better explain course content to students from their home country, they avoided using it when other students were present.

In adapting to a conservative institutional environment, ITAs probably also were responding to the myth that only native speakers correctly use English (Kasztalska, 2018). Hence, they worked toward adapting their vocabulary, accents, or ways of using English to a specific American form, without asking students to put any effort to work with their linguistic differences. They also did not consider using their knowledge of different ways of using English as a tool to 
teach different communication styles and language usage to students. One participant even highlighted the helpful experience of speaking English with people from diverse linguistic and cultural backgrounds at a university in their home country, yet did not see this as a teaching or learning opportunity with American students. These findings highlight missed opportunities for ITAs to use their linguistic potential to contribute to the institutional discourse.

Interestingly, the disciplinary context of engineering intersected with ITAs' foreignness characterized by a lack of English proficiency, mitigating some of the linguistic challenges. As noted by one participant, the science- and math-heavy content in engineering courses (Cunningham \& Kelly, 2017) allowed them to bypass their communication challenges by using representations in written form when facing problems with oral communication.

Our findings have important implications for ITAs, students taught by ITAs, and academic programs. Perhaps the most important takeaway from these findings is that there remains a lack of awareness when it comes to the untapped benefits that could be derived from the linguistic and cultural heterogeneity that ITAs bring to U.S. universities. These benefits include ITAs' own professional and personal development, and an increased global perspective in students and academic programs. Academic cultures that attempt to maintain a monolithic form of English can adversely impact ITAs' personal and professional socialization in academic discourses by focusing on adapting to another's culture and a racialized version of English instead of building a global identity (Sterzuk, 2015). Moreover, such academic cultures do not realistically prepare students for the increasingly global workforce, the repercussions of which are particularly higher for engineering graduates who often work in teams spread across countries (Stevens et al., 2014). Overall, promotion of an inauthentic standard English contradicts the diversity of the world we live and work in, thus defeating the internationalization goals of academic programs that can be achieved through an exchange of cultural and linguistic values and practices (Ryan, 2011).

Our findings point to the need for creating academic contexts that support and encourage the linguistic diversity brought by ITAs. One way to meet this goal is to engage ITAs in reflective practices to question the fallacy that only the locals correctly speak English (Zheng, 2017) and recognize the value of World Englishes in advancing academic discourse (Kasztalska, 2018). ITAs can also be introduced to a course on translanguaging strategies similar to Canagarajah's (2011). At the same time, faculty and students can be explicitly made aware of the importance of being exposed to linguistic diversity through professional development workshops and encouraged to view ITAs as a source of this diversity. For ITAs who do not have sufficient prior exposure to English and hence face communication challenges, opportunities such as conversation groups and meet-ups can be created so that they can practice and improve their oral communication through informal interactions (Zhou, 2009).

This study explored how the academic context shapes linguistic experiences of ITAs from Asian and African countries. Building on its findings, similar comparative studies that include White ITAs from Western countries can be conducted in the future to better understand how racial identities shape ITAs' 
English-language experiences. Future work can also be done to understand faculty and students' attitudes toward translanguaging and World Englishes so that holistic steps can be taken to create institutional environments that support and encourage linguistic diversity.

\section{ACKNOWLEDGMENTS}

We would like to acknowledge the research grant from Virginia Tech Graduate Research Development Program to compensate the participants for their time. We also thank Dr. Marie Paretti for her support during various stages of the study and Dr. Amy Hermundstad Nave for her help in conducting reliability checks during data analysis. However, any findings, recommendations, or opinions presented in this paper represent only the authors' views.

\section{REFERENCES}

Adebayo, C. T., \& Allen, M. (2020). The experiences of international teaching assistants in the US classroom. Journal of International Students, 10(1), 69-83. https://doi.org/10.32674/jis.v10i1.1086

Agrawal, A., McNair, L. D., \& Paretti, M. C. (2018). Teaching in a foreign land: Experiences of international teaching assistants in U.S. engineering classrooms. Proceedings of the 125th Annual ASEE Conference and Exposition, Salt Lake City, UT.

Arshavskaya, E. (2015). International teaching assistants' experiences in the US classrooms: Implications for practice. Journal of the Scholarship of Teaching and Learning, 15(2), 56-69. https://doi.org/10.14434/josotl.v15i2.12947

Bauer, G. (1996). Addressing special considerations when working with international teaching assistants. In J. D. Nyquist \& D. H. Wulff (Eds.), Working effectively with graduate assistants (pp. 84-103). SAGE.

Bedolla, L. G. (2007). Intersections of inequality: Understanding marginalization and privilege in the post-civil rights era. Politics \& Gender, 3(2), 232-248. https://doi.org/10.1017/S1743923X07000050

Bruning, M. J., Bystydzienski, J., \& Eisenhart, M. (2015). Intersectionality as a framework for understanding diverse young women's commitment to engineering. Journal of Women and Minorities in Science and Engineering, 21(1), 1-26. https://doi.org/10.1615/JWomenMinorScienEng.2014007345

Canagarajah, S. (2011). Codemeshing in academic writing: Identifying teachable strategies of translanguaging. The Modern Language Journal, 95(3), 401-417. https://doi.org/10.1111/j.1540-4781.2011.01207.x

Chiang, S.-Y. (2011). Pursuing a response in office hour interactions between US college students and international teaching assistants. Journal of Pragmatics, 43(14), 3316-3330. https://doi.org/10.1016/j.pragma.2011.07.001

Chiang, S.-Y. (2016). “Is this what you're talking about?": Identity negotiation in international teaching assistants' instructional interactions with US college students. Journal of Language, Identity \& Education, 15(2), 114-128. https://doi.org/10.1080/15348458.2016.1137726 
Collins, P. H., \& Bilge, S. (2016). Intersectionality. Polity Press.

Crenshaw, K. (1989). Demarginalizing the intersection of race and sex: A black feminist critique of antidiscrimination doctrine, feminist theory and antiracist politics. University of Chicago Legal Forum, 1989(1), 139-167.

Cunningham, C. M., \& Kelly, G. J. (2017). Epistemic practices of engineering for education. Science Education, 101(3), 486-505. https://doi.org/10.1002/ sce. 21271

Fitch, F., \& Morgan, S. E. (2003). "Not a lick of English": Constructing the ITA identity through student narratives. Communication Education, 52(3-4), 297-310. https://doi.org/10.1080/0363452032000156262

Hancock, A.-M. (2007). When multiplication doesn't equal quick addition: Examining intersectionality as a research paradigm. Perspectives on Politics, 5(1), 63-79. https://doi.org/10.1017/S1537592707070065

Hebbani, A., \& Hendrix, K. G. (2014). Capturing the experiences of international teaching assistants in the US American classroom. New Directions for Teaching and Learning, 2014(138), 61-72. https://doi.org/10.1002/tl.20097

Heng, T. T. (2019). Understanding the heterogeneity of international students' experiences: A case study of Chinese international students in US universities. Journal of Studies in International Education, 23(5), 607-623. https:// doi.org/10.1177/1028315319829880

Institute of International Education. (2019). Open doors data. http://www. iie.org/Research-and-Publications/Open-Doors/Data\#.WKYZLm8rKUk

Jenkins, J. (2014). English as a lingua franca in the international university: The politics of academic English language policy. Routledge.

Jonassen, D. H. (2014). Engineers as problem solvers. In A. Johri \& B. M. Olds (Eds.), Cambridge handbook of engineering education research (pp. 103-118). Cambridge University Press.

Jones, V., Kim, Y., \& Ryu, W. (2020). Intersecting roles of authority and marginalization: International teaching assistants and research university power dynamics. Journal of International Students, 10(2), 483-500. https://doi.org/10.32674/jis.v10i2.757

Kasztalska, A. (2018). International teaching assistants in the composition classroom: From World Englishes to translingualism and beyond. Journal of Language, Identity \& Education, 18(3), 161-175. https://doi.org/ 10.1080/15348458.2018.1545584

Lee, J. J., \& Rice, C. (2007). Welcome to America? International student perceptions of discrimination. Higher Education, 53(3), 381-409. https://doi.org/10.1007/s10734-005-4508-3

Lindblom-Ylänne, S., Trigwell, K., Nevgi, A., \& Ashwin, P. (2006). How approaches to teaching are affected by discipline and teaching context. Studies in Higher Education, 31(3), 285-298. https://doi.org/10.1080/ 03075070600680539

Little, D. K. (2016). Students-as-informant: Investigating the use of feedback by international teaching assistants [Unpublished doctoral dissertation]. The Ohio State University. 
Munro, M. J. (2003). A primer on accent discrimination in the Canadian context. TESL Canada Journal, 20(2), 38-51. https://doi.org/10.18806/tesl.v20i2.947

Okahana, H., \& Zhou, E. (2019). Graduate enrollment and degrees: 2008 to 2018. Council of Graduate Schools. https://cgsnet.org/ckfinder/userfiles/ files/CGS_GED18_Report_web.pdf

Pimentel, C. (2011). The color of language: The racialized educational trajectory of an emerging bilingual student. Journal of Latinos and Education, 10(4), 335-353. https://doi.org/10.1080/15348431.2011.605686

Ryan, J. (2011). Teaching and learning for international students: Towards a transcultural approach. Teachers and Teaching, 17(6), 631-648. https://doi.org/10.1080/13540602.2011.625138

Sterzuk, A. (2015). 'The standard remains the same': Language standardisation, race and othering in higher education. Journal of Multilingual and Multicultural Development, 36(1), 53-66. https://doi.org/10.1080/01434632. 2014.892501

Stevens, R., Johri, A., \& O'connor, K. (2014). Professional engineering work. In A. Johri \& B. Olds (Eds.), Cambridge handbook of engineering education research (pp. 119-137). Cambridge University Press.

Wang, H. (2016). International teaching assistants' professional identity development at a US University: A multiple case study perspective [Unpublished doctoral dissertation]. The University of Alabama.

Zheng, X. (2017). Translingual identity as pedagogy: International teaching assistants of English in college composition classrooms. The Modern Language Journal, 101(S1), 29-44. https://doi.org/10.1111/modl.12373

Zhou, J. (2009). What is missing in the international teaching assistants training curriculum? The Journal of Faculty Development, 23(2), 19-24.

Zhou, J. (2014). Managing anxiety: A case study of an international teaching assistant's interaction with American students. Journal of International Students, 4(2), 177-190.

ASHISH AGRAWAL, $\mathrm{PhD}$, is a visiting faculty member in the Centre for Curriculum Development, Planning and Coordination at National Institute of Technical Teachers Training and Research, Chennai, India. His major research interests lie in the areas of faculty development, student and faculty experiences in STEM, sociology of education, and critical pedagogies. It should be noted that all work for this paper was done by him at his prior institutions-Virginia Tech and University of Cape Town. He can be reached via email at ashishag@vt.edu.

LISA D. MCNAIR, PhD, is a professor in the Department of Engineering Education and director of the Center for Educational Networks and Impacts (CENI) at Virginia Tech. Her major research interests lie in the areas of transdisciplinarity, liberatory makerspaces, STEAM outreach and broader impacts, and reflective practice. She can be reached via email at lmcnair@vt.edu. 